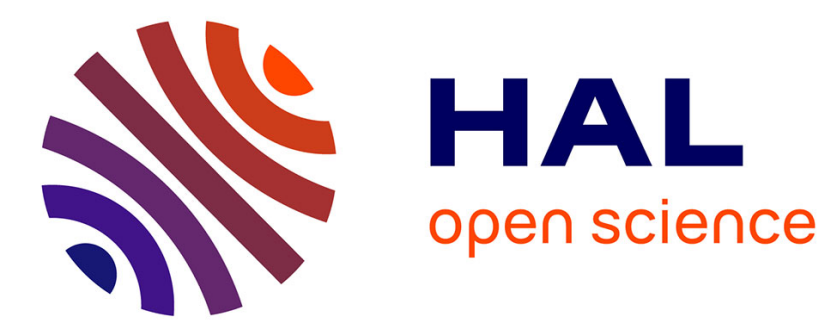

\title{
Urban structure and environmental externalities
}

Sophie Legras, Camille Regnier

\section{To cite this version:}

Sophie Legras, Camille Regnier. Urban structure and environmental externalities. 2014. hal02801303

\section{HAL Id: hal-02801303 \\ https://hal.inrae.fr/hal-02801303}

Preprint submitted on 5 Jun 2020

HAL is a multi-disciplinary open access archive for the deposit and dissemination of scientific research documents, whether they are published or not. The documents may come from teaching and research institutions in France or abroad, or from public or private research centers.
L'archive ouverte pluridisciplinaire HAL, est destinée au dépôt et à la diffusion de documents scientifiques de niveau recherche, publiés ou non, émanant des établissements d'enseignement et de recherche français ou étrangers, des laboratoires publics ou privés. 
UMR 1041 INRA - AGROSUP

\title{
CESAER
}

Centre d'Economie et Sociologie appliquées à l'Agriculture et aux Espaces Ruraux

\section{Urban Structure and Environmental Externalities}

\author{
Camille Regnier
}

Sophie Legras

\section{Working Paper $2014 / 2$}




\title{
Urban Structure and \\ Environmental Externalities
}

\author{
Camille Regnier* Sophie Legras
}

INRA UMR 1041 CESAER

April 30, 2014

\begin{abstract}
The objective of this paper is to analyze policy design for air pollution management in the spatial context of urban development. We base our analysis on the paper of Ogawa and Fujita (1982), which offers a proper theoretical framework of non-monocentric urban land use using static microeconomic theory where the city structure is endogenous. First, we show that when households internalize industrial pollution in their residential location choice, spatialization within the city is reinforced. This impacts directly the emissions of greenhouse gases from commuting. Then, we analyze policy instruments in order to achieve optimal land use pattern when the policy maker has to manage both industrial and commuting related polluting emissions, that interact through the land market.
\end{abstract}

JEL classification : Q53, D62, R14

Keywords : Environmental externalities, Land use pattern, Air pollution

* corresponding author. Email adress : camille.regnier@dijon.inra.fr, 26 boulevard du Dr Petitjean BP 87999 21079 Dijon Cedex, FRANCE. Tel : +33 (0) 380772439 


\section{Introduction}

In a world were distance is almost eliminated by innovations in telecommunication, people live closer and closer to each other : more than half the human population resides in urban areas (UNFPA, 2007). However living in cities involves health risks, in particular relating to degraded air quality. A study conducted by the European Commission reveals that pollution is responsible for forty-two thousand deaths per year in European cities (Watkiss et al., 2009). The World Health Organization recently highlighted that air pollution lowers life expectancy by seven months for a thirty-year-old individual in Paris (Declercq et al., 2012). The recent pollution event in Paris in March 2014, that lead to the implementation of traffic restrictions, put in perspective the debated role of multiple pollution sources, both local and regional, to the pollution load measured in Ile-de-France. The question of how to manage emission sources from different sectors is of crucial importance. Indeed, atmospheric pollution (PM10, PM5, NOx, etc.) and greenhouse gases (GHG) are emitted by various sectors, in particular transport, residential and industrial, at different levels.

Environmental economists have been concerned with the deterioration of air quality for a long time and analyses of public policies for air pollution management in an aspatial context are numerous . Analyses of multiple interacting pollution sources are more scarce. Caplan and Silva (2005) introduced the notion of "correlated externalities" in a context where a single source is responsible for emitting multiple pollutants that may have local or regional impacts. They analyzed the properties of different policy instruments to manage efficiently such correlated externalities in the context of a global federation with decentralized leadership in a series of papers (Caplan and Silva (2005); Caplan (2006); Caplan and Silva (2007)). However, there exist different types of correlations between atmospheric pollutants, since they can interact during or after the production process in various manners : complement or substitute abatement technologies, interactions between stocks, interacting damage, etc. A range of papers tackle this issue, framed in the context of GHG policy design, based on dynamic models of pollutant accumulation where the interactions between pollutants are described in different manners (Yang (2006); Moslener and Requate (2007, 2009); Legras (2011)). However, they all point out to the importance of carefully characterizing the interactions between pollutants in the design of policy instruments. A recent paper by Ren et al. (2011) addresses the correlation between pollutants only through markets, "interacting externalities", and analyze how this interaction affects the design of taxes to manage each externality. They show that the optimal second best policy depends on the nature of the market relationship between the goods whose production causes the externalities. All these studies are particularly relevant regarding urban air quality because there are several sources of pollution in cities : mostly industries and transports, and several types of pollutants : local pollution such as particular matter or heavy metals and global pollutants such as greenhouse gases. However, the previously cited papers do not study air pollution in an explicit spatial model, concealing then some issues specific to cities. 
This paper examines the policy implications of multiple simultaneous externalities in a spatially explicit context of urban development. It extends the above-cited literature to a spatial framework, and introduces multiple environmental issues in an urban economics framework.

Some studies have analyzed air pollution in an explicit spatial setting, either by studying pollution caused by industry or by studying pollution caused by transport, which are the two main sources of the deterioration of urban air quality. Henderson (1977) is the first to study air pollution caused by industrial sources in a monocentric setting. Arnott et al. (2008) and Kyriakopoulou and Xepapadeas (2011) extend the study of industrial pollution to non-monocentric cities. Kyriakopoulou and Xepapadeas (2013) and Verhoef and Nijkamp (2002) also develop this model to incorporate agglomerations economies. The important result shared by all these papers is the existence of a defensive behavior by households : as they dislike pollution, households choose to locate farther from polluting firms. But problems can arise when there is an excessive defensive behavior by households : the tendency to choose a more remote location entails for example larger travel costs and increased car use. The use of cars as a means of transportation is also directly responsible for emissions of pollution in cities. Robson (1976) shows that the equilibrium land use pattern is distorted from optimum because of transport pollution. Then policy instruments, such as a tax on commuting, should be implemented to decentralize the optimum, (McConnell and Malhon, 1982; Robson, 1976; Verhoef and Nijkamp, 2003).

To the best of our knowledge, interactions between industrial pollution and transport pollution have not been explicitly examined yet in the economic literature. However these two externalities are linked through the land market. Indeed air pollution resulting from industries' emissions affect the locational decision of households by pushing them away from polluting firms, while an optimal policy instrument in the case of pollution from commuting leads to more concentrated cities. If we take into account both types of pollution into a same model the conclusion is different and the effect of a tax on transport is in contradiction with the defensive behavior by households suffering from industrial pollution. Using the words of Bennear and Stavins (2007), the multiple markets failure are jointly reinforcing, meaning that the correction of one market failure exacerbates welfare loss from the other.

This paper departs from the previous literature by developing a theoretical model incorporating two environmental externalities that interact through land market in an explicit spatial setting. The objectives of this paper are : (i) to identity the effect of industrial pollution on household choice of localization when neither employment nor residential location are specified a priori, (ii) to assess the level of transport pollution resulting from the equilibrium city structure, (iii) and to find the optimal policy mix to manage both industrial and transport pollutions. 
The remainder of the paper is organized as follows. Section 2 presents the structure of the model, based on Ogawa and Fujita (1982) model of linear city with endogenous center. Section 3 deals with the equilibrium land use pattern, and section 4 focuses on the design of an optimal policy mix, composed of an industrial pollution abatement norm and a tax on commuting paid by households. Section 5 concludes.

\section{The model}

A linear city lies on a uni-dimensional space $X=]-\infty,+\infty[$. At each location $x \in X$, the quantity of available land is equal to one. Two types of agents interact inside the city : firms and households. Each household provides one unit of labor to a firm, and receives a wage in exchange.

Firms produce a good using a polluting technology and export it outside the city. Households consume a good $z$ imported from outside and are affected by industrial pollution. In addition, both types of agents compete for land, owned by absentee landowners, either for residential or production purposes. These interactions take place through labor and land markets, both of which are assumed to be perfectly competitive at each point $x \in X$ of the city.

Commuting by households from their place of residence to their workplace generates GHG emissions, proportional to the aggregate distance travelled. They do not affect the households directly but are accounted for by the policy maker (see section 4). Commuting also contributes to polluting emissions (particular matter, NOx, etc.) that affect households' utility, but we do not incorporate them in our model. Indeed, our model of a linear city with one transportation means and a single road does not allow us to capture the localized effects of traffic-related pollution in a satisfactory manner (see for instance Schindler and Caruso (2014) for a discussion on this issue). In the simplest manner, without accounting for distance-based emission factors (such as the cold engine effect), they would be incorporated as proportional to the amount of traffic passing by each residential location, which decreases with the distance from the CBD. Hence, they would reinforce the defensive behavior of households that induces them to locate further from the CBD. A more detailed model would be necessary to fully grasp the emission/exposure tension in the management of traffic-related local pollution.

\section{$2.1 \quad$ Households}

We assume that there are $\mathrm{N}$ identical households in the city, where $\mathrm{N}$ is exogenously determined. We focus on a closed-city model, useful to study the internal structure of cities. All households have identical preferences and derive utility from the consumption of a composite 
good $Z$, land $S_{h}$, and perceived environmental quality $E$. The amount of land consumed by each household, $S_{h}$, is assumed to be given exogenously. We choose a quasi-linear functional form to describe households' utility :

$$
U\left(Z(x), S_{h}, E(x)\right)=Z(x)+E(x)+\gamma \ln S_{h}
$$

Households choose a residential location $x$ and a job site $x_{w}$ to maximize their utility under a budget constraint. Each household provides one unit of labor to a business firm located in $x_{w}$ and earns a wage $W\left(x_{w}\right)$ in return. This wage is used to pay a land rent $R(x)$, and to consume a composite commodity. The composite commodity is chosen as a numeraire so its price $p_{z}=1$. Each household commutes to the firm everyday at a cost $t$ per kilometer travelled between residential location and job site. Environmental quality is considered as a spatial attribute of housing, which affects the households' utility function directly but not its budget constraint.

Since all households are assumed to be identical, in equilibrium they must all achieve the same maximum utility level, independent of location. The common maximum utility level, called the equilibrium utility and denoted $U^{*}$, is the solution of the following program :

$$
\begin{cases}\max _{x, x_{w}} & U\left(Z(x), S_{h}, E(x)\right) \\ \text { s.t. } & W\left(x_{w}\right)=R(x) S_{h}+Z(x)+t\left|x-x_{w}\right|\end{cases}
$$

The environmental quality function is defined at each point $x$ by a linear function ${ }^{1}$ :

$$
E(x)=\bar{E}-\int_{X}[e-\eta|x-y|] b(y) d y
$$

Where $\bar{E}$ is an ambiant quality level with no pollution, $e$ represents the quantity of pollution emitted by one firm, $\eta$ is a measure of dispersion of pollution into the atmosphere, $|x-y|$ is the distance between households located at $x$ and firms located at $y$, and $b(y)$ is the density function of firms at location $y$. Households located in $x$ suffer from a negative effect of pollution emitted by firms located at $y$. As emissions disperse into the atmosphere at a constant rate, households can choose to benefit from a better environmental quality if they locate far away from firms. However, by choosing a location farther from firms, households bear a higher transport cost. Transport cost acts as a centripetal force, while pollution acts as a centrifugal one. Households' well-being is determined by the trade-off between the accessibility to the workplace and the amount of environmental quality at the residential location.

This trade-off appears in the bid-rent function of households, which is a generalized form

\footnotetext{
${ }^{1}$ The choice of a linear function allows us to compute in a comprehensible manner the following results analytically. Until a given point, similar results can be found using an exponential functional form.
} 
of the bid rent function originally defined by Alonso (1964) in the context of a monocentric city. The individual bid-rent function of a household located at $x$ gives the highest price that he is willing to pay for one unit of land at $x$ while deriving the utility level $U^{*}$ and given the wage profile $W\left(x_{w}\right)$. It is expressed as follows :

$$
\Psi(x) \equiv \Psi\left(x \mid W\left(x_{w}\right), U^{*}\right)=\max _{x_{w}}\left\{\frac{1}{S_{h}}\left[W\left(x_{w}\right)-t\left|x-x_{w}\right|-Z^{*}\left(S_{h}, E(x), U^{*}\right)\right]\right\}
$$

Where $Z^{*}\left(S_{h}, E(x), U^{*}\right)$ is the solution to $U\left(Z(x), S_{h}, E(x)\right)=U^{*}$ and represents the amount of composite good necessary to achieve the equilibrium utility level $U^{*}$ when lot size is equal to $S_{h}$ and environmental quality to $E(x)$. With the specified utility function defined in (1) we obtain :

$$
\Psi^{*}(x)=\max _{x_{w}}\left\{\frac{1}{S_{h}}\left[W\left(x_{w}\right)-t\left|x-x_{w}\right|-U^{*}+E(x)+\gamma \ln \left(S_{h}\right)\right]\right\}
$$

Note that here, each household locating at $x$ optimally chooses its job site $x_{w}$, considering the trade-off between commuting cost $t\left|x-x_{w}\right|$ and wage $W\left(x_{w}\right)$. The equilibrium wage profile is given $b^{2}$ :

$$
W(x)=W(0)-t x
$$

Then, using (3) we conclude that at the equilibrium the bid-rent function of households is :

$$
\Psi^{*}(x)=\frac{1}{S_{h}}\left[W(x)-U^{*}+E(x)+\gamma \ln \left(S_{h}\right)\right]
$$

The bid-rent of households depends positively on wage and the environmental quality, but negatively on transport cost, revealing the trade-off between accessibility and environmental quality.

\subsection{Business firms}

We suppose that there are $M$ identical firms. Each firm produces one good using land, labor, and a polluting technology. Production output is exported from the city at a unitary price. Following Ogawa and Fujita (1982), we assume that the amounts of land $S_{b}$ and labor $L_{b}$ used for production by each firm are fixed. We assume that there is no unemployment in the city, so that at the equilibrium we have the following relation :

$$
M=N / L_{b}
$$

\footnotetext{
${ }^{2}$ Due to the no cross commuting property, the equilibrium wage profile is a linear function of the distance to the center. Refer to (Ogawa and Fujita, 1980) for proofs of these two propositions. They are not altered by the introduction of industrial pollution in the model as the consumption of environmental quality does not enter into the budget constraint and the net income remains the same.
} 
Firms benefit from agglomeration economies, measured by the locational potential function $F(x)$ defined by :

$$
F(x)=\int_{X}[\alpha-\tau|x-y|] b(y) d y
$$

where $b(y)$ is the density of business firms at $y$, and $|x-y|$ is the distance between firms locating at $x$ and firms locating at $y$.

Firms use a polluting technology. They have to pay a cost $C(a)$ to abate an amount $a$ of pollution $^{3}$. The level of abatement is the difference between the laissez-faire level of pollution emission $e^{e}$ and a lower level given by $\bar{e}: a=e^{e}-\bar{e}$. At the laissez-faire situation, abatement level and abatement cost both equal zero.

Each firm seeks to maximize its profit and solves the following program :

$$
\max _{x} \pi=F(x)-R(x) S_{b}-W(x) L_{b}-C(a)
$$

From the maximization problem we can define the bid-rent function of firms. It is the maximum land rent that a business firm is willing to pay to locate at $x$ while deriving a profit $\pi^{*}$ and given the distribution of firms $b(x)$. It is written as follows :

$$
\Phi^{*}(x) \equiv \Phi\left(x \mid b(x), W(x), \pi^{*}\right)=\frac{F(x)-\pi^{*}-W(x) L_{b}-C(a)}{S_{b}}
$$

Markets are perfectly competitive then profit is driven to zero at equilibrium, and firms choose their amount of abatement freely so the bid-rent function is rewritten as :

$$
\Phi^{*}(x)=\frac{F(x)-W(x) L_{b}}{S_{b}}
$$

The bid-rent function of firms depends positively on the locational potential but negatively on wage.

\subsection{Equilibrium conditions}

Equilibrium land use describes a state of the urban system that shows no propensity to change. It implies that there is no utility to gain by changing location, neither for firms nor for households. At the equilibrium, land is allocated to the highest bidder. Beyond the city's limits, there is only agricultural land, characterized by an exogenous agricultural land rent $R_{a}$.

\footnotetext{
${ }^{3}$ The cost of abatement is positive, and increasing and convex with respect to the level of abatement : $C(a)>0, C^{\prime}(a)>0, C^{\prime \prime}(a)>0$, for every $a>a^{e}$ where $a^{e}$ corresponds to the laissez-faire situation.
} 
Each equilibrium spatial structure of the city is described by a system where the unknowns are the household density function $h(x)$, the firm density function $b(x)$, the land rent profile $R(x)$, the wage profile $W(x)$, the commuting pattern $P\left(x, x_{w}\right)$, and the utility level $U^{*}$, with

$$
P\left(x, x_{w}\right)=\frac{\text { number of households locating at } x \text { and commuting to job site } x_{w}}{\text { total number } h(x) \text { of households locating at } x}
$$

The necessary and sufficient conditions for the system to be an equilibrium land use pattern are summarized as follows :

(i) Land market equilibrium conditions at each $x$ :

$$
\begin{aligned}
& R(x)=\max \left\{\Psi^{*}(x), \Phi^{*}(x), R_{a}\right\} \\
& R(x)=\Psi^{*}(x) \quad \text { if } \quad h(x) \geq 0 \\
& R(x)=\Phi^{*}(x) \quad \text { if } \quad b(x) \geq 0 \\
& R(x)=R_{a} \quad \text { at the urban fringe } \\
& S_{h} h(x)+S_{b} b(x) \leq 1 \\
& S_{h} h(x)+S_{b} b(x)=1 \quad \text { if } \quad R(x)>R_{a}
\end{aligned}
$$

(ii) Labor market equilibrium condition at each $x$ :

$$
b(x) L_{b}=\int_{X} h(y) P(y, x) d y
$$

(iii) Total unit number constraints :

$$
\int_{X} h(x) d x=N, \quad \int_{X} b(x) d x=M
$$

(iv) Non-negativity constraints :

$$
\begin{gathered}
h(x) \geq 0, \quad b(x) \geq 0, \quad R(x) \geq 0, W(x) \geq 0, \quad 1 \geq P\left(x, x_{w}\right) \geq 0, \\
\int_{X} P\left(x, x_{w}\right) d x_{w}=1
\end{gathered}
$$

\section{Equilibrium land use pattern with industrial pollution}

In this section we examine the conditions under which different urban configurations are the equilibrium market outcome, an extension of the analysis of (Ogawa and Fujita, 1980) to the case where households internalize industrial pollution. The endogenous urban configuration may be concentrated (a monocentric city), dispersed (a completely residential/industrial mixed city) or an intermediate (a city with both specialized and mixed residential and industrial areas). We analyze how the internalization of industrial pollution by households modifies 
their residential location choice, hence how the equilibrium urban structure is affected. We also derive the total distance travelled in each urban configuration, to assess the intensity of GHG emissions resulting from households' and firms' location choices.

\subsection{Monocentric urban configuration}

We start with the basic monocentric configuration, which corresponds to a city where the majority of households lives in the suburbs while firms occupy the center. Formally, we assume that the origin is the center of the city. All firms are located around 0 between $-f_{1 m}$

and $f_{1 m}$, the business district (BD). Households are located in two zones, between $-f_{1 m}$ and - $f_{2 m}$ and between $f_{1 m}$ and $f_{2 m}$, the residential areas (RA). Beyond urban fringes $-f_{2 m}$ and $f_{2 m}$ there are only agricultural lands. Figure 1 represents the monocentric configuration of the city.

Figure 1 about here.

We assume that the city is perfectly symmetric, then it is sufficient to examine the equilibrium conditions on the right-half of the city, where $x \geq 0$. Since land uses are exclusive, the following density functions apply :

$$
\begin{array}{ll}
h(x)=1 / S_{h}, \quad b(x)=0, & \forall x \in R A \\
h(x)=0, & b(x)=1 / S_{b}, \quad \forall x \in B D
\end{array}
$$

Thanks to the total unit number constraints and the full employment assumptions, we can derive the equilibrium center boundary $f_{1 m}$ and the urban fringe $f_{2 m}$ :

$$
f_{1 m}=\frac{S_{b} M}{2}, \quad f_{2 m}=\frac{M}{2}\left(S_{b}+L_{b} S_{h}\right)
$$

Using its definition in equation (5), the locational potential function in the monocentric city is :

$$
F(x)=\left\{\begin{array}{lll}
\alpha M-\frac{\tau}{S_{b}}\left(f_{1 m}^{2}+x^{2}\right) & \text { if } & x \in\left[0, f_{1 m}\right] \\
\alpha M-\frac{2 \tau}{S_{b}} x f_{1 m} & \text { if } & x \in\left[f_{1 m}, f_{2 m}\right]
\end{array}\right.
$$

$F(x)$ is decreasing and concave with $x$ on $\mathrm{BD}$ and decreasing and linear on $\mathrm{RA}$, meaning that agglomeration externalities are stronger when firms are close to each other : the potential location function acts as a centripetal force for firms.

To define the environmental quality in the monocentric configuration, we use equation (2) and the definition of industrial density. We obtain the following environmental quality function : 


$$
E(x)=\left\{\begin{array}{lll}
\bar{E}-e M+\frac{\eta}{S_{b}}\left(f_{1 m}^{2}+x^{2}\right) & \text { if } & x \in\left[0, f_{1 m}\right] \\
\bar{E}-e M+\frac{2 \eta}{S_{b}} x f_{1 m} & \text { if } & x \in\left[f_{1 m}, f_{2 m}\right]
\end{array}\right.
$$

$E(x)$ is increasing and convex in $x$ on BD and increasing and linear on RA. Environmental quality perceived by households located at $x$ is inversely correlated with the aggregation of pollution emitted by firms in the city, given by $e M$. However it increases with the distance to the center because pollution disperses into the atmosphere at a rate $\eta$.

The property of no cross-commuting allows us to rewrite the equilibrium conditions on the land market as follows :

$$
\begin{aligned}
& R(x)=\Phi^{*}(x) \geq \Psi^{*}(x) \quad \forall x \in\left[0, f_{1 m}\right] \\
& R(x)=\Phi^{*}(x)=\Psi^{*}(x) \quad \text { at } \quad x=f_{1 m} \\
& R(x)=\Psi^{*}(x) \geq \Phi^{*}(x) \quad \forall x \in\left[f_{1 m}, f_{2 m}\right] \\
& R(x) \quad=\Psi^{*}(x)=R_{a} \quad \text { at } \quad x=f_{2 m}
\end{aligned}
$$

where $\Psi^{*}(x)$ and $\Phi^{*}(x)$ are given by equation (4) and (6) respectively. Then the equilibrium conditions on the land market can be simplified :

$$
\begin{aligned}
& R(0)=\Phi^{*}(0) \geq \Psi^{*}(0) \\
& R\left(f_{1 m}\right)=\Phi^{*}\left(f_{1 m}\right)=\Psi^{*}\left(f_{1 m}\right) \\
& R\left(f_{2 m}\right)=R_{a}=\Psi^{*}\left(f_{2 m}\right) \geq \Phi^{*}\left(f_{2 m}\right)
\end{aligned}
$$

Which implies

$$
\begin{aligned}
& \Phi^{*}(0)-\Phi^{*}\left(f_{1 m}\right) \geq \Psi^{*}(0)-\Psi^{*}\left(f_{1 m}\right) \\
& \Phi^{*}\left(f_{1 m}\right)-\Phi^{*}\left(f_{2 m}\right) \geq \Psi^{*}\left(f_{1 m}\right)-\Psi^{*}\left(f_{2 m}\right)
\end{aligned}
$$

Using equations (4) and (6), we can rewrite (10) and (11) as follows, where $A_{m}$ and $A_{m}^{\prime}$ correspond to the conditions derived in (Ogawa and Fujita, 1982) when there is no environmental externality and $B_{m}$ and $B_{m}^{\prime}$ appear with the introduction of pollution in the model :

$$
\begin{gathered}
t \leq \underbrace{\frac{S_{h}}{S_{b}+S_{h} L_{b}} \cdot \frac{\left(F(0)-F\left(f_{1 m}\right)\right)}{f_{1 m}}}_{A_{m}}+\underbrace{\frac{S_{b}}{S_{b}+S_{h} L_{b}} \cdot \frac{\left(E\left(f_{1 m}\right)-E(0)\right)}{f_{1 m}}}_{B_{m}} \\
t \leq \underbrace{\frac{S_{h}}{S_{b}+S_{h} L_{b}} \cdot \frac{\left(F\left(f_{1 m}\right)-F\left(f_{2 m}\right)\right)}{\left(f_{2 m}-f_{1 m}\right)}}_{A_{m}^{\prime}}+\underbrace{\frac{S_{b}}{S_{b}+S_{h} L_{b}} \cdot \frac{\left(E\left(f_{2 m}\right)-E\left(f_{1 m}\right)\right)}{\left(f_{2 m}-f_{1 m}\right)}}_{B_{m}^{\prime}}
\end{gathered}
$$

$B_{m}$ and $B_{m}^{\prime}$ are positive constants, which means that the condition on $t$ is easier to sustain. Moreover, they increase with the value of $\eta$. Industrial pollution pushes households to 
locate farther from the business district, and leads to a greater spatialisation of activities.

Since $A_{m}+B_{m}<A_{m}^{\prime}+B_{m}^{\prime}$, we obtain only one conditions on $t$ for the monocentric configuration to constitute an equilibrium :

$$
t \leq \frac{1}{2} \frac{\left(S_{h} \tau+S_{b} \eta\right) N}{L_{b}\left(S_{b}+S_{h} L_{b}\right)}=\overline{t_{1}}
$$

This leads to the following proposition.

Proposition 1 The monocentric configuration is more likely an equilibrium when households internalize industrial pollution.

The pollution effect reinforces the locational potential effect, the former acting as a centripetal force for households and the latter as a centrifugal force for firms.

The total distance travelled in a monocentric configuration is given by the aggregation of households' commuting trips :

$$
D_{m}\left(x, x_{w}\right)=\int_{0}^{f_{1 m}} \int_{f_{1 m}}^{f_{2 m}} P\left(x, x_{w}\right)\left(x-x_{w}\right) d x d x_{w}
$$

where the commuting pattern $P\left(x, x_{w}\right)$ in the monocentric city case is :

$$
P\left(x, x_{w}\right)=\frac{\left(f_{2 m}-f_{1 m}\right) / S_{h}}{f_{1 m} / S_{b}} \cdot \frac{1}{1 / S_{h}}
$$

This leads to :

$$
D_{m}=\frac{1}{2} S_{b} f_{2 m}\left(f_{2 m}-f_{1 m}\right)^{2}
$$

The total distance travelled in a monocentric urban configuration increases with the population, residential and industrial lot sizes, and labor intensity.

\subsection{Completely mixed urban configuration}

Now we analyze a situation where households and firms coexist at every point $x$ in the city. This type of configuration may be considered as analogous to a highly densified city in a model with endogenous lot size : firms and households are close to each other and both types of configurations present the same characteristics. The limits of the city are given by the frontiers $-f_{1 c}$ and $f_{1 c}$. There is only one area between these two limits called the integrated district $(I D)$, as represented in figure 2, where households' residential location and job site are the same $x=x_{w}$.

Figure 2 about here. 
This implies no commuting. Consequently, the equilibrium condition in the labor market is satisfied, and the total distance travelled $D_{c}$ is equal to zero. Under this configuration, the density function of firms and households are :

$$
h(x)=\frac{L_{b}}{S_{b}+S_{h} L_{b}}, \quad b(x)=\frac{1}{S_{b}+S_{h} L_{b}}, \quad \forall x \in\left[-f_{1 c}, f_{1 c}\right]
$$

We focus again only on the right-half of the city where $x \geq 0$. The environmental quality perceived by households located at $x$ is given by :

$$
E(x)=\bar{E}-e M+\frac{\eta}{S_{b}+S_{h} L_{b}}\left(f_{1}^{2}+x^{2}\right) \quad \forall x \in\left[0, f_{1 c}\right]
$$

Environmental quality is increasing and convex inside $I D$. The locational potential function is expressed as follows :

$$
F(x)=\alpha M-\frac{\tau}{S_{b}+S_{h} L_{b}}\left(f_{1 c}^{2}+x^{2}\right) \quad \forall x \in\left[0, f_{1 c}\right]
$$

It is decreasing and concave inside $I D$. In the land market the equilibrium conditions are written :

$$
\begin{array}{cc}
R(x)=\Psi^{*}(x)=\Phi^{*}(x) & \forall x \in\left[0, f_{1 c}\right] \\
R(x)=R_{a} & \text { at } \quad x=f_{1 c}
\end{array}
$$

From (4), (6) and (18a) we obtain the wage profile on the integrated district :

$$
W(x)=\frac{S_{h} F(x)+S_{b}\left(U^{*}-\gamma \ln S_{h}\right)-\overbrace{S_{b} E(x)}^{C}}{S_{b}+S_{h} L_{b}}
$$

Part $\mathrm{C}$ is due to the introduction of environmental externalities in the model : the equilibrium wage decreases with environmental quality. In this configuration households cannot internalize the pollution damage by choosing a location farther from firms, so firms must offer a higher wage to provide an incentive for households to locate where environmental quality is low.

Plugging (19) into (4) or (6), we obtain the equilibrium land rent :

$$
R(x)=\frac{F(x)-L_{b}\left(U^{*}-\gamma \ln S_{h}\right)+L_{b} E(x)}{S_{b}+S_{h} L_{b}}
$$

Again, the rent function is increasing with the level of environmental quality $W(x)$ is positively correlated with $F(x)$ and negatively correlated with $E(x)$. It implies that the wage $W(x)$ is a strictly concave function of $x$. As there is no commuting in the completely mixed configuration, households have no incentive to change their job site only if $\left|W^{\prime}(x)\right| \leq t$. This condition is 
equivalent to $W^{\prime}\left(f_{1}\right) \geq-t$ because of the strict concavity of $W(x)$. Then, from this condition and with equations (16) and (17) we obtain that the completely mixed configuration is an equilibrium if :

$$
t \geq A_{c}+B_{c}=\frac{N \tau S_{h}}{\left(S_{b}+S_{h} L_{b}\right) L_{b}}+\frac{N \eta S_{b}}{\left(S_{b}+S_{h} L_{b}\right) L_{b}}=\frac{N\left(\tau S_{h}+\eta S_{b}\right)}{\left(S_{b}+S_{h} L_{b}\right) L_{b}}=\overline{t_{2}}
$$

where $A_{c}$ is the condition without pollution as in Ogawa and Fujita (1982), and $B_{c}$ is due to the introduction of pollution in the model. $B_{c}$ is a positive constant meaning that the condition on $t$ for the completely mixed urban configuration to be an equilibrium is stronger.

Proposition 2 The completely mixed urban configuration is less likely an equilibrium when households internalize industrial pollution.

Even if the locational potential $\tau$ is very low, the completely mixed urban configuration might not be an equilibrium because of the presence of the negative environmental externality, which pushes households far from polluting firms.

\subsection{Incompletely mixed urban configuration}

An incompletely mixed urban configuration is a generalization of the monocentric and of the completely mixed configuration. There are three sections in the city. As the city is perfectly symmetric we focus only on the right-half. Between 0 and $f_{1 i}$, firms and households are mixed in the integrated district (ID). The business district (BD), between $f_{1 i}$ and $f_{2 i}$, and the residential area (RA), between $f_{2 i}$ and $f_{3 i}$, are specialized areas. Figure 3 represents the incompletely mixed city structure.

Figure 3 about here.

The city boundaries are given by :

$$
f_{1 i} \in\left(0, \frac{S_{b}+S_{h} L_{b}}{2 L_{b}} N\right), \quad f_{2 i}=\frac{S_{h} L_{b}}{S_{b}+S_{h} L_{b}} f_{1 i}+\frac{S_{b} N}{2 L_{b}}, \quad f_{3 i}=\frac{S_{b}+S_{h} L_{b}}{2 L_{b}} N
$$

It is straightforward to note that the incompletely mixed urban configuration approaches the monocentric configuration as $f_{1 i}$ tends to zero, and it approaches the completely mixed configuration as $f_{1 i}$ tends to $N\left(S_{b}+S_{h} L_{b}\right) / 2 L_{b}$. Each segment of the city is characterized by the density, environmental quality and locational potential functions described in Appendix 1.

The equilibrium conditions in the land market for the incompletely mixed urban configuration allow us to derive the equilibrium value of $f_{1 i}$ as well as the conditions for this urban configuration to constitute an equilibrium. They are summarized, for $x \geq 0$, as follow :

$$
R(x)=\Phi^{*}(x)=\Psi^{*}(x) \quad \forall x \in\left[0, f_{1}\right]
$$




$$
\begin{aligned}
& R(x)=\Phi^{*}(x) \geq \Psi^{*}(x) \quad \forall x \in\left[f_{1 i}, f_{2 i}\right] \\
& R(x)=\Phi^{*}(x)=\Psi^{*}(x) \quad \text { at } \quad x=f_{2 i} \\
& R(x)=\Psi^{*}(x) \geq \Phi^{*}(x) \quad \forall x \in\left[f_{2 i}, f_{3 i}\right] \\
& R(x)=\Psi^{*}(x)=R_{a} \quad \text { at } \quad x=f_{3 i}
\end{aligned}
$$

Where $\Psi^{*}(x)$ and $\Phi^{*}(x)$ are given by (4) and (6) respectively.

Appendix 2 presents the resolution process that leads to the following conditions on $t$ for the incompletely mixed configuration to be an equilibrium :

$$
\begin{aligned}
& t=\frac{S_{h}}{S_{b}+S_{h} L_{b}} \cdot \frac{\left(F\left(f_{1 i}\right)-F\left(f_{2 i}\right)\right)}{f_{2 i}-f_{1 i}}+\underbrace{\frac{S_{b}}{S_{b}+S_{h} L_{b}} \cdot \frac{\left(E\left(f_{2 i}\right)-E\left(f_{1 i}\right)\right)}{f_{2 i}-f_{1 i}}}_{B_{i}} \\
& t \leq \frac{S_{h}}{S_{b}+S_{h} L_{b}} \cdot \frac{\left(F\left(f_{1 i}\right)-F\left(f_{3 i}\right)\right)}{\left(f_{3 i}-f_{1 i}\right)}+\underbrace{\frac{S_{b}}{S_{b}+S_{h} L_{b}} \cdot \frac{\left(E\left(f_{3 i}\right)-E\left(f_{1 i}\right)\right)}{f_{3 i}-f_{1 i}}}_{B_{i}^{\prime}}
\end{aligned}
$$

Parts $B_{i}$ and $B_{i}^{\prime}$ are positive constants capturing the effect of an environmental externality on the equilibrium outcome. Finally, no commuting in ID implies again that $\left|W^{\prime}(x)\right| \leq t$ for $x \in I D$, which is equivalent to the following conditions :

$$
t \geq \frac{S_{h}}{S_{b}+S_{h} L_{b}} F^{\prime}\left(f_{1 i}\right)+\frac{S_{b}}{S_{b}+S_{h} L_{b}} E^{\prime}\left(f_{1 i}\right)
$$

Plugging the definitions of $F(x)$ and $E(x)$ into (23a), we can compute the value of the integrated district's limit, $f_{1 i}$ :

$$
f_{1 i}=\frac{t\left(S_{b}+S_{h} L_{b}\right)^{2}}{\tau S_{h}+\eta S_{b}}-\frac{\left(S_{b}+S_{h} L_{b}\right) M}{2}
$$

It is clear that with pollution $(\eta>0)$, the integrated district is smaller than without pollution. Then, the spatialization of activities tends to be more important with negative environmental externalities. At the equilibrium, the city is less integrated and more spatialized.

Using the definition of $f_{1 i}$ and (23b) and (24), we obtain the following necessary conditions on $t$ for the incompletely mixed land use pattern to be an equilibrium :

$$
\overline{t_{1}} \leq t \leq \overline{t_{2}}
$$

Proposition 3 With the presence of a negative environmental externality caused by industrial pollution, the integrated district of an incompletely mixed city is smaller, while the business district and the residential area are larger at the equilibrium. Furthermore, the values of $t$ for which the incompletely mixed urban configuration is an equilibrium are higher than in the no 
pollution case.

The total distance travelled is given by the following function :

$$
D_{i}\left(x, x_{w}\right)=\int_{f_{1}}^{f_{2}} \int_{f_{2}}^{f_{3}} P\left(x, x_{w}\right)\left(x-x_{w}\right) d x d x_{w}
$$

Following the same reasoning as in section (3.1), the commuting pattern is written :

$$
P\left(x, x_{w}\right)=\frac{\left(f_{3 i}-f_{2 i}\right) / S_{h}}{\left(f_{2 i}-f_{1 i}\right) / S_{b}} \cdot \frac{1}{1 / S_{h}}
$$

Plugging this expression into (27) gives the total distance travelled in the incompletely mixed configuration :

$$
D_{i}=\frac{1}{2}\left(f_{3 i}-f_{2 i}\right)^{2}\left(f_{3 i}-f_{1 i}\right) S_{b}
$$

Proposition 4 With the presence of a negative environmental externality caused by industrial pollution, the aggregate commuting distance is larger in a monocentric configuration than in the incompletely mixed case.

Refer to Appendix 3 for the demonstration. Then, the defensive behavior exhibited by households towards industrial pollution generates higher commuting damage, that they do not incorporate but that enters the policy maker's program. The next section investigates the policy implications of accounting for both industrial and commuting damage.

\section{Policy implications}

The presence of externalities leads to non-optimal equilibrium land use. When they maximize profits firms do not take into account households' disutility caused by their emissions of industrial pollution. The resulting defensive behavior of households is responsible for an increase in car use, hence in GHG emissions. This section explores the issue of how to design appropriate incentive shemes to induce households and firms to make socially optimal decisions.

Specifically, we consider two types of policy instruments : the first one used to manage car pollution is a tax on commuting, and the second one used to control industrial pollution is an abatement norm.

The tax on commuting is a price-based instrument and creates direct incentives for household to limit their commuting distance. In practice, this instrument can take several forms : an urban toll as in London or Singapore, or a kilometric tax as recently experimented in Bruxelles. In our model, the commuting tax takes the form of a cost $T$ linearly proportional 
to the distance travelled by each household.

The abatement norm on industrial emissions is a quantity-based instrument. The social planner chooses a minimal level of pollution abatement that all firms must respect. If they do not comply with the norm, firms face the risk to pay a fine ${ }^{4}$. In practice, such norms are enforced, for instance in the USA as part of the Clean air act : the National Emission Standard for Hazardous Air Pollution (NESHAP) for example imposes a regulatory limit on the emission of industrial firms. In Europe, the European Commission also adopted in 2010 a new legislation to lower the norm on industrial emissions (such as nitrogen oxide or heavy metals). In our model, the abatement norm is denoted $\bar{a}$ and is superior to the laissez-faire level of abatement, so $\bar{a}>0$.

The effects of each instrument on the city structure and on welfare is specified below. From now on we consider only the case of incompletely mixed urban configuration in order to have a global view of the impact of public policies on pollution externalities and on the urban structure. Again, we also consider only the right hand side of the city where $x \geq 0$.

\subsection{Commuting tax, abatement norm and equilibrium land use pattern}

The tax on commuting impacts the budget constraint of households directly. It changes the utility maximization program of households and leads to new bid-rent functions. Following the same reasoning as in section 3 and denoting the unitary $\operatorname{tax} T$ with $T \geq 0$, the new bid-rent function of households is written as follows :

$$
\Psi^{*}(x)=\max _{x_{w}}\left\{\frac{1}{S_{h}}\left[W\left(x_{w}\right)-(t+T)\left|x-x_{w}\right|-U^{*}+E(x)+\gamma \ln \left(S_{h}\right)\right]\right\}
$$

A tax on commuting lowers the bid-rent function of households by increasing their transport expenditures.

The norm on firms' emissions impacts directly the profit function of firms. The cost $C(\bar{a})$ of abating more than in the laissez-faire situation is positive. The new bid-rent function of firms is given by :

$$
\Phi^{*}(x)=\frac{F(x)-W(x) L_{b}-C(\bar{a})}{S_{b}}
$$

A norm on industrial emissions lowers the bid-rent function of firms by increasing their pollution abatement cost.

Following the same resolution process as in the previous section, we obtain these conditions on $\mathrm{t}$ :

\footnotetext{
${ }^{4}$ We assume in the remainder of the paper that it is sufficiently high to ensure complete compliance
} 


$$
\begin{gathered}
t+T=\frac{S_{h}}{S_{b}+S_{h} L_{b}} \cdot \frac{F\left(f_{1}^{T}\right)-F\left(f_{2}^{T}\right)}{f_{2}^{T}-f_{1}^{T}}+\frac{S_{b}}{S_{b}+S_{h} L_{b}} \cdot \frac{E\left(f_{2}^{T}\right)-E\left(f_{1}^{T}\right)}{f_{2}^{T}-f_{1}^{T}} \\
t+T \leq \frac{S_{h}}{S_{b}+S_{h} L_{b}} \cdot \frac{F\left(f_{1}^{T}\right)-F\left(f_{3}\right)}{\left(f_{3}-f_{1}^{T}\right)}+\frac{S_{b}}{S_{b}+S_{h} L_{b}} \cdot \frac{E\left(f_{3}\right)-E\left(f_{1}^{T}\right)}{f_{3}-f_{1}^{T}} \\
t+T \geq \frac{S_{h}}{S_{b}+S_{h} L_{b}} F^{\prime}\left(f_{1}^{T}\right)+\frac{S_{b}}{S_{b}+S_{h} L_{b}} E^{\prime}\left(f_{1}^{T}\right)
\end{gathered}
$$

The first terms on the right-hand sides of equations (32a), (32b) and (33) are equivalent to those of equations (23a), (23b), and (24). Only the second terms are modified : the total cost of transportation, which is the addition of the transport cost and the commuting tax, should now be taken into account :

$$
\overline{t_{1}} \leq t+T \leq \overline{t_{2}}
$$

Plugging the definitions of $F(x)$ and $E(x)$ into (32a), we derive the new integrated district's limit :

$$
f_{1}^{T}=\frac{(t+T)\left(S_{b}+S_{h} L_{b}\right)^{2}}{\tau S_{h}+\eta S_{b}}-\frac{\left(S_{b}+S_{h} L_{b}\right) M}{2}
$$

Comparing (25) and (35) highlights the following results : the implementation of a commuting tax raises the size of the integrated district. The tax increases transport expenditures of households and induces them to locate closer to their place of work.

The abatement norm $\bar{a}$ has no direct effect on the city structure. The level of industrial pollution decreases simultaneously in every point $x$ of the city, then environmental quality is proportionally higher everywhere. The norm does not change the city structure, but it affects the level of industrial pollution directly and therefore the damage and the equilibrium utility. We develop theses results in the following section.

\subsection{Commuting tax, abatement norm and social welfare}

Implementing policy instruments to manage air pollution has a direct impact on wages and the equilibrium utility level (see Appendix 4). Indeed, households located in the residential area have to bear higher transport expenditures due to the commuting tax. Then when they choose their workplace $x_{w}$ optimally they consider the trade-off between the new commuting cost $(t+T)\left(x-x_{w}\right)$ and the wage $W\left(x_{w}\right)$. Equilibrium wages are also impacted by the increase in firms' abatement cost. Firms offer lower wages because a part of their profit is allocated 
to the payment of this cost. The new equilibrium wage profile is then lower in each point $x$ of the city. The equilibrium utility level is impacted negatively by the decreases in wages. However, the norm on industrial emissions raises environmental quality in each point $x$ of the city, which increases utility. Hence there is a tradeoff between higher environmental quality and lower net revenues. To assess the aggregate impact on social welfare, we now look at how policy instruments affect the environmental damage from GHG emissions and industrial pollution.

Commuting by households from their place of residence $x$ to their workplace $x_{w}$ generates GHG emissions. The environmental damage created by commuting is then proportional to the total distance travelled in the city. If $k$ is the unitary measure of pollution by commuting, the total environmental damage created by GHG emissions, denoted TDC, is :

$$
T D C=k D_{I}(T)=k \cdot \frac{1}{2} S_{b}\left(f_{3}-f_{1}^{T}\right)\left(f_{3}-f_{2}^{T}\right)^{2}
$$

It is not affected by the abatement norm since this damage is linked to the land use pattern.

The second source of pollution, coming from industry, is partly internalized by households who decide to locate farther from polluting firms. However, each household only internalizes the damage created by industrial pollution at its own place of residence, whereas pollution emitted by one firm has an impact on the whole city. Then the social cost of industrial pollution is greater than the individual cost. The total damage created by industrial pollution, denoted $T D F$, is the aggregation of individual damage at each point $x(x \geq 0)$ of the city :

$$
T D F=\int_{X} \int_{X}[e-\eta|x-y|] b(y) d y d x
$$

Simplifying this equation, we get the following expression :

$$
T D F(T, \bar{a})=(e-\bar{a}) M f_{3}-\frac{\eta}{S_{b}}\left[\frac{\left(f_{2}^{T}\right)^{3}-\left(f_{1}^{T}\right)^{3}}{3}+\left(f_{2}^{T}-f_{1}^{T}\right) f_{3}^{2}\right]-\frac{\eta}{S_{b}+S_{h} L_{b}}\left[\frac{\left(f_{1}^{T}\right)^{3}}{3}+f_{1}^{T} f_{3}^{2}\right]
$$

Both the abatement norm and the commuting tax impact industrial pollution damage, either directly by inducing the firms to reduce their pollution load or indirectly by affecting the residential location choice of households, hence their exposure level.

\section{Commuting tax and welfare}

The variation of utility with respect to the level of commuting tax is given by :

$$
\frac{\partial U_{T}^{*}}{\partial T}=\frac{2\left(S_{b}+S_{h} L_{b}\right)}{L_{b}\left(\tau S_{h}+\eta S_{b}\right)}\left[(T+t)\left(S_{b}+S_{h} L_{b}\right) L_{b}-N\left(\tau S_{h}+\eta S_{b}\right)\right]<0
$$


We know from equation (34) that this expression is always negative. The equilibrium utility level is negatively correlated with the commuting tax : households which stay in the residential area have to bear higher transport expenditures. Households which relocate inside the integrated district do not pay any commuting cost anymore but suffer from a lower environmental quality. In a general way, as utility must be equal in each point $x$ of the city, the equilibrium utility level with a commuting tax is lower than without tax.

Now, we analyze the variation of each type of environmental damage with respect to the commuting tax level.The differentiation of the total commuting damage with respect to $\mathrm{T}$ gives the following expression :

$$
\frac{\partial T D C}{\partial T}=-\frac{3}{2} \frac{k S_{b}\left(S_{b}+S_{h} L_{b}\right)^{2} S_{h}^{2}\left((T+t)\left(S_{b}+S_{h} L_{b}\right) L_{b}-N\left(\tau S_{h}+\eta S_{b}\right)\right)^{2}}{\left(S_{b} \eta+S_{h} \tau\right)^{3}}<0
$$

As expected, the commuting damage is decreasing with $\mathrm{T}$, as the introduction of the tax pushes part of the households to relocate inside the integrated district. Then, a lower number of households have to commute to work every day, leading to a reduced amount of GHG emitted.

The variation of industrial damage with respect to the commuting tax is given by :

$$
\begin{array}{r}
\frac{\partial T D F}{\partial T}=\frac{\eta S_{h}\left(S_{b}+S_{h} L_{b}\right)}{\left(\eta S_{b}+\tau S_{h}\right)^{3}}\left[(T+t)\left(S_{b}+S_{h} L_{b}\right) L_{b}-N\left(\tau S_{h}+\eta S_{b}\right)\right] \\
\cdot\left[(T+t)\left(S_{b}+S_{h} L_{b}\right)\left(S_{b}+2 L_{b} S_{h}\right)-N S_{h}\left(\tau S_{h}+\eta S_{b}\right)\right]
\end{array}
$$

The sign of the above expression depends on the value of $t+T$ (refer to Appendix 5) : for low values, this expression is always positive. Then, the total industrial damage is positively correlated with a tax on commuting. The introduction of such a tax leads to a rise in the size of the integrated district : a larger part of households suffers directly from industrial pollution, which entails an increase in the industrial damage. However, for larger values of $\mathrm{T}$, the above expression becomes negative : increasing the commuting tax has the impact of decreasing the damage related to industrial damage.

Proposition 5 A commuting always reduces commuting damage, however it may increase industrial damage and decreases the utility level. Then a commuting tax must be used alone only if the welfare gain entailed by the decrease in commuting damage is greater than the loss caused by the increase in industrial damage and the decrease in utility.

Next we assess if these negative effects of a commuting tax may be compensated by coupling the commuting tax with an norm on industrial pollution abatement. 


\section{Industrial pollution abatement norm and welfare}

The variation of utility with respect to the industrial pollution norm is given by :

$$
\frac{\partial U_{T}^{*}}{\partial a}=\frac{\left(N-\frac{\partial C(a)}{\partial a}\right)}{L_{b}}
$$

The partial derivative of abatement cost with respect to the abatement level $a$ is positive. Then, the expression above is positive if $N>\frac{\partial C(a)}{\partial a}:$ a well calibrated abatement norm $\bar{a}$ allows to increase households' utility level. However, if the norm is too strict the utility level will decrease since the wage loss will exceed the environmental quality gain.

The abatement norm does not affect commuting damage; however the variation of industrial damages with respect to the norm is given by :

$$
\frac{\partial T D F}{\partial a}=-\frac{1}{2} \frac{N^{2}\left(S_{b}+S_{h} L_{b}\right)}{L_{b}^{2}}<0
$$

Unsurprisingly, this expression is always negative : a higher level of abatement entails a lower industrial damage for the whole city.

Proposition 6 A pollution abatement norm always reduces industrial damage, it has no effect on commuting damage and it may allow to increase the utility level as long as the gain from a higher environmental quality is greater than the wage loss entailed by increasing firms' abatement costs. If the norm is correctly chosen by the social planner, it increases the level of social welfare.

To manage efficiently both car-related and industrial pollutions, the social planner should mix the use of a commuting tax and an industrial abatement norm. Indeed, a commuting tax alone can solely reduce commuting damage, to the detriment of household utility and industrial damage. On the contrary, an abatement norm used alone cannot reduce commuting damage. If both policy instruments are used simultaneously and correctly calibrated, the commuting tax is useful to reduce commuting damage and the undesired effects of this tax on utility and industrial damage is compensated by the beneficial effects of the norm. The social welfare reaches its maximum level. However, if the gain of reducing commuting damage is too low, the use of an abatement norm alone can be the best solution to increase welfare.

\subsection{An efficient policy mix}

Let's now consider the design of an efficient policy mix $\left\{a^{*}, T^{*}\right\}$ that would ensure that the policy maker maximizes the following social welfare function :

$$
S W=N U_{T}^{*}-\gamma_{c} T D C-\gamma_{f} T D F
$$


where $\gamma_{c}$ and $\gamma_{f}$ are the social weights associated with each term of damage.

Proposition 7 The optimal abatement norm is not affected by $\gamma_{c}$ and is positively correlated with $\gamma_{f}$. For $\gamma_{f}<\overline{\gamma_{f}}$ and $\gamma_{c}>\overline{\overline{\gamma_{c}}}$, the optimal tax rate is compatible with an incompletely mixed equilibrium, and it is positively affected by $\gamma_{c}$ : an increase in the social valuation of the damage relating to commuting induces an increase in the policy instrument designed to manage it. The impact of $\gamma_{f}$ depends on the value of $\gamma_{c}$ : for high enough values, the tax rate is positively affected; otherwise an increase in the social valuation of industrial pollution has the impact of decreasing the optimal commuting tax rate.

Proof 1 See Appendix 6 for the demonstration and for the values of the social weights' thresholds.

On the one hand, as an abatement norm does not affect commuting damage but always reduces industrial damage, the optimal level of the norm is not affected by the social weight associated to the former damage and is increasing with the social weight associated to the latter. In other terms, the higher the social valuation of the industrial damage, the higher the optimal abatement norm implemented to manage it.

On the other hand, the commuting tax always reduces the damage associated to commuting but may increase the industrial damage. Then, if the social valuation of the industrial damage is low enough, the optimal commuting tax increases with the social valuation of the commuting damage : the increase in industrial damage created by the commuting tax is lower than the social welfare gain from to the decrease in commuting damage. However, if the social valuation of the industrial damage is high enough, the effect of an increase in industrial damage due to the increasing commuting tax is greater than the effect of the decrease in commuting damage. Then, the optimal commuting tax rate is negatively correlated with social valuation of the commuting damage. In the same way, if the social valuation of the commuting damage is low, then the benefits of implementing a commuting tax are low. In that case, the optimal tax rate decreases with the increase in industrial damage's social weight. However, when the social valuation of commuting damage is high, the optimal commuting tax rate must increase with the social valuation of industrial damage, even if this means a larger amount of industrial damage.

These results highlight the correlated impacts that the social valuations of damage have on the optimal policy mix. They point out the importance of carefully assessing the effects of the implementation of policy instruments; in this specific spatial context, the instruments under study have an impact of the location choices of households and firms, hence on the city structure. In this respect, the case of the commuting tax is particularly striking : implemented to manage the GHG emissions due to households' commuting patterns, it has a direct impact 
on households' location choice, hence on aggregate GHG emissions. However, by inducing a relocation of households closer to their workplace, it also has an impact on their exposure to industrial pollution. This illustrates the potential adverse effect of partial policy design in a spatial context.

\section{Conclusion}

We developped an urban economics model in which firms and households are free to chose were to locate, so that the city structure is endogeneous. Our first aim was to assess the impact of introducing environmental externalities in the framework developped by (Ogawa and Fujita, 1982) : how does the consideration of industrial pollution affect the internal structure of cities? We show that when firms emit pollution that is at least partially internalised by households, then the monocentric city structure is more likely an equilibrium : the effect of pollution on households' location choice has the capacity to make the monocentric city an attractive option even when agglomeration economies are low. Also, it takes very high transport costs to make the completely mixed city structure an equilibrium solution. Finally, industrial pollution induces a more spatialized incompletely mixed city structure.

Our second aim was to investigate environmental policy design in this spatial context. Besides industrial pollution, a typical point-source pollution, partially internalized by households, we also considered the impact of households' commuting pattern in terms of GHG emissions. The latter externality is not internalized by households, but is of prime importance to the policy maker. We consider the design of two types of instruments to manage the two environmental externalities at stake : an industrial abatement norm and a commuting tax. They bear different characteristics, such as the direct or indirect nature of their impact on the city structure. We put in perspective how they may also have an indirect impact of the social damage associated with the externality they are not implemented to manage : indeed, the commuting tax, by the effect it has on households' residential location choice, affect their exposure to industrial pollution, hence the social damage from this point-source pollution. Then the optimal policy mix depends on the social valuation of each type of damage accounted for by the policy maker, and partial policy design in this spatial context may have detrimential impacts on individual and social welfares.

Our analysis rests on a series of simplifying assumptions that call for further studies on the correlation between environmental externalities in a spatial context. We chose a simple production side model, to concentrate on households and their reaction to the exposure to industrial pollution; this constrained the range of policy instruments that we could study to manage the emissions of industrial pollution. A straightforward extension of this work could consist in introducing a more detailed production function to allow us to analyse more 
complex policy options to manage industrial pollution. Also, as evoked earlier, we concentrate on one type of commuting-related externality, GHG emission, without accounting for more localized pollution issues. This would necessitate a more detailed city model, at least in two dimension, to fully explore the emission/exposure tension at the city scale.

\section{References}

Alonso, W. (1964). Location and Land use : toward a general theory of land rent. Harvard University Press, Cambridge, Mass.

Arnott, R., Hochman, O., and Rausser, G. C. (2008). Pollution and land use: optimum and decentralization. Journal of Urban Economics, 64(2):390-407.

Bennear, L. and Stavins, R. (2007). Second-best theory and the use of multiple policy instruments. Environmental and Resource economics, 37(1):111-129.

Caplan, A. (2006). A comparison of Emission Taxes and Permit Markets for Controlling Correlated Externalities. Environmental and Resource Economics, 34:471-492.

Caplan, A. and Silva, E. (2005). An efficient mechanism to control correlated externalities: redistributive transferts and the coexistence of regional and global pollution permit markets. Journal of Environmental Economics and Management, 49:68-82.

Caplan, A. and Silva, E. (2007). An equitable, efficient and implementable scheme to control global carbon dioxide emissions. Int Tax Public Finance, 14:263-279.

Declercq, C., Pascal, M., Chanel, O., Corso, M., Ung, A., Pascal, L., Blanchard, M., Larrieu, S., and Medina, S. (2012). Impact sanitaire de la pollution atmosphérique dans neuf villes françaises : Résultat du projet Aphekom.

Henderson, J. V. (1977). Externalities in a spatial context : the case of air pollution. Journal of Public Economics, 7:89-110.

Kyriakopoulou, E. and Xepapadeas, A. (2011). Spatial location decision under environmental policy and housing externalities. Environmental Economics and Policy Studies, 13(3):195217.

Kyriakopoulou, E. and Xepapadeas, A. (2013). Environmental policy, first nature advantage and the emergence of economic clusters. Regional Science and Urban Economics, 43(1):101116.

Legras, S. (2011). Incomplete model specification in a multi-pollutants setting: The case of climate change and acidification . Resource and Energy Economics, 33:527-543.

McConnell, V. and Malhon, S. (1982). Auto pollution and congestion in a urban model : An analysis of alternative strategies. Journal of Urban Economics, 11:11-31. 
Moslener, U. and Requate, T. (2007). Optimal abatement in dynamic multi-pollutant problems when pollutants can be complements or substitutes. Journal of Economic Dynamics and Control, 31:2293-2316.

Moslener, U. and Requate, T. (2009). The dynamics of optimal abatement strategies for multiple pollutants - an illustration in the greenhouse. Journal of Environmental Economics and Management, 68:1521-1534.

Ogawa, H. and Fujita, M. (1980). Equilibrium land use patterns in a nonmonocentric city. Journal of Regional Science, 20(4):455-475.

Ogawa, H. and Fujita, M. (1982). Multiple equilibria and structural transition of nonmonocentric urban configurations. Regional Science and Urban Economics, 12:161-196.

Ren, X., Fullerton, D., and Braden, J. B. (2011). Optimal taxation of externalities interacting through markets: A theoretical general equilibrium analysis. Resource and Energy Economics, 33:496-514.

Robson, A. J. (1976). Two models of urban air pollution. Journal of Urban Economics, $3: 264-284$.

Schindler, M. and Caruso, G. (2014). Urban compactness and the trade-off between air pollution emission and exposure: Lessons from a spatially explicit theoretical model. Computers, Environment and Urban Systems, 45:13-23.

UNFPA (2007). State of the world population 2007 : Unleashing the potential of urban growth.

Verhoef, E. T. and Nijkamp, P. (2002). Externalities in urban sustainability: environmental versus localization-type agglomeration externalities in a general spatial equilibrium model of a single-sector monocentric industrial city. Ecological Economics, 40(2):157-179.

Verhoef, E. T. and Nijkamp, P. (2003). Externalities in the urban economy. Tinbergen Institute Discussion Paper, No. 03-078/3.

Watkiss, P., Pye, S., and Holland, M. (2009). CAFE CBA : Baseline analysis 2000 to 2020.

Yang, Z. (2006). Negatively correlated local and global stock externalities: tax or subsidy? Environment and Development Economics , 11:301-316.

\section{Appendix 1}

The density, locational potential and environmental quality functions in the incompletly mixed case are : 
- In the integrated district :

$$
\begin{aligned}
& h(x)=\frac{L_{b}}{S_{b}+S_{h} L_{b}}, \quad b(x)=\frac{1}{S_{b}+S_{h} L_{b}} \\
& E(x)=\bar{E}-e M+\left\{\frac{\eta}{S_{b}}\left(f_{2 i}^{2}-f_{1 i}^{2}\right)+\frac{\eta}{S_{b}+S_{h} L_{b}}\left(f_{1 i}^{2}+x^{2}\right)\right\} \\
& F(x)=\alpha M-\left\{\frac{\tau}{S_{b}}\left(f_{2 i}^{2}-f_{1 i}^{2}\right)+\frac{\tau}{S_{b}+S_{h} L_{b}}\left(f_{1 i}^{2}+x^{2}\right)\right\}
\end{aligned}
$$

- In the business district :

$$
\begin{aligned}
& h(x)=0, \quad b(x)=\frac{1}{S_{b}} \\
& E(x)=\bar{E}-e M+\left\{\frac{\eta}{S_{b}}\left(f_{2}^{2}-2 f_{1} x+x^{2}\right)+\frac{2 \eta}{S_{b}+S_{h} L_{b}} f_{1} x\right\} \\
& F(x)=\alpha M-\left\{\frac{\tau}{S_{b}}\left(f_{2 i}^{2}-2 f_{1 i} x+x^{2}\right)+\frac{2 \tau}{S_{b}+S_{h} L_{b}} f_{1 i} x\right\}
\end{aligned}
$$

- In the residential area :

$$
\begin{aligned}
& h(x)=\frac{1}{S_{h}}, \quad b(x)=0 \\
& E(x)=\bar{E}-e M+\left\{\frac{2 \eta}{S_{b}}\left(f_{2 i}-f_{1 i}\right) x+\frac{2 \eta}{S_{b}+S_{h} L_{b}} f_{1 i} x\right\} \\
& F(x)=\alpha M-\left\{\frac{2 \tau}{S_{b}}\left(f_{2 i}-f_{1 i}\right) x+\frac{2 \tau}{S_{b}+S_{h} L_{b}} f_{1 i} x\right\}
\end{aligned}
$$

\section{Appendix 2}

As in the case of a completely mixed urban configuration, from (4), (6) and (22a), we obtain the wage profile $W(x)$ in the integrated district. On the residential area, the wage profile is a linear function of distance. To summarize, the wage profile in the city is given by :

$$
W(x)=\left\{\begin{array}{lll}
\frac{S_{h} F(x)+S_{b}\left(U^{*}-\gamma \ln S_{h}\right)-S_{b} E(x)}{S_{b}+S_{h} L_{b}} & \text { if } & x \in\left[0, f_{1 i}\right] \\
W\left(f_{1}\right)-t\left(x-f_{1}\right) & \text { if } & x \in\left[f_{1 i}, f_{3 i}\right]
\end{array}\right.
$$

Using (4) and the second part of (37), we can compute the value of $W(x)$ at $f_{1 i}$ depending on the level of equilibrium utility $U^{*}$. Knowing that this value of $W\left(f_{1 i}\right)$ must be equal to the value in the first part of (37), we can determine the equilibrium utility level $U^{*}$ as a function of $f_{1 i}$ and $f_{3 i}$ :

$$
U^{*}=\frac{F\left(f_{1 i}\right)}{L_{b}}+\frac{S_{b}\left(E\left(f_{3 i}\right)-E\left(f_{1 i}\right)\right)-\left(S_{b}+S_{h} L_{b}\right)\left(S_{h} R_{a}+t\left(f_{3 i}-f_{1 i}\right)\right)}{S_{h} L_{b}}+\gamma \ln S_{h}+E q\left(f_{3 i}\right)
$$

The functional form of $F(x)$ and $E(x)$ allow us to say that $F(x)$ is strictly concave on $B D$ and linear on $R A$ and $E(x)$ is convex on $B D$ and linear on $R A$. Then, we conclude that $R(x)$ will be concave on $B D$ and linear on $R A$, so the rest of the land market conditions are 
equivalent to :

$$
\begin{aligned}
& R(x)=\Phi^{*}(x)=\Psi^{*}(x) \\
& \text { at } \quad x=f_{1 i}, f_{2 i} \\
& R(x)=\Psi^{*}(x)=R_{a} \\
& \text { at } \quad x=f_{3 i}
\end{aligned}
$$

\section{Appendix 3}

To compare the aggregate commuting distances in the monocentric and incompletely mixed cases, we plug the definition of $f_{1 i}, f_{2 i}$ and $f_{3 i}$ in equation (15) and (29) :

$$
D_{m}-D_{i}=\frac{1}{16} \frac{S_{b} S_{h}^{2}\left(L_{b} S_{h}+S_{b}\right)}{L_{b}\left(S_{b} \eta+S_{h} \tau\right)^{3}}\left[2 t L_{b}\left(\left(L_{b} S_{h}+S_{b}\right)-N\left(S_{b} \eta+S_{h} \tau\right)\right] D_{1}\right.
$$

where $D_{1}$ is a second-order equation in $t$, positive over positive $t$ :

$$
D_{1}=4 t L_{b}\left(L_{b} S_{h}+S_{)}\left[t L_{b}\left(\left(L_{b} S_{h}+S_{b}\right)-N\left(S_{b} \eta+S_{h} \tau\right)\right]+\left(S_{b} \eta+S_{h} \tau\right)\left[7 N^{2}-6 t L_{b}\left(L_{b} S_{h}+S_{b}\right)\right]\right.\right.
$$

Hence, $D_{m}-D_{i}$ is of the sign of the expression in brackets, which is positive in an incompletly mixed equilibrium.

\section{Appendix 4}

Following the same reasoning as in appendix 2, we determine the new wages profile, denoted $W_{T}(x)$, and the utility level, denoted $U_{T}^{*}$, at the equilibrium :

$$
\begin{aligned}
& W_{T}(x)=\left\{\begin{array}{lll}
\frac{S_{h}(F(x)-C(\bar{e}))+S_{b}\left(U^{*}-\gamma \ln S_{h}-E(x)\right)}{S_{b}+S_{h} L_{b}} & \text { if } & x \in\left[0, f_{1}^{t}\right] \\
W\left(f_{1}\right)-(t+T)\left(x-f_{1}\right) & \text { if } & x \in\left[f_{1}^{t}, f_{3}\right]
\end{array}\right. \\
& U_{T}^{*}=\frac{F\left(f_{1}^{T}\right)-C(\bar{e})}{L_{b}}+\frac{S_{b}\left(E\left(f_{3}\right)-E\left(f_{1}^{t}\right)\right)-\left(S_{b}+S_{h} L_{b}\right)\left(S_{h} R_{a}+(t+T)\left(f_{3}-f_{1}^{T}\right)\right)}{S_{h} L_{b}}+\gamma \ln S_{h}+E\left(f_{3}\right)
\end{aligned}
$$

\section{Appendix 5}

The differential of the damage created by industrial pollution with respect to the tax is given by :

$$
\begin{aligned}
\frac{\partial T D F}{\partial T}= & \overbrace{\frac{\eta S_{h}\left(S_{b}+S_{h} L_{b}\right)}{\left(\eta S_{b}+\tau S_{h}\right)^{3}}}^{1} \overbrace{\left[(T+t)\left(S_{b}+S_{h} L_{b}\right) L_{b}-N\left(\tau S_{h}+\eta S_{b}\right)\right]}^{2} \\
& \cdot \underbrace{\left[(T+t)\left(S_{b}+S_{h} L_{b}\right)\left(S_{b}+2 L_{b} S_{h}\right)-N S_{h}\left(\tau S_{h}+\eta S_{b}\right)\right]}_{3}
\end{aligned}
$$


All parameters are positive, then part 1 of the above equation is always positive. Conditions (32b) ensures that :

$$
T+t \leq \frac{N\left(\tau S_{h}+\eta S_{b}\right)}{L_{b}\left(S_{b}+S_{h} L_{b}\right)}=\overline{t_{2}}
$$

So part 2 is always negative. The sign of $\frac{\partial T D F}{\partial T}$ depends on the sign of part 3 . Part 3 is negative if :

$$
t+T \leq \frac{N\left(\tau S_{h}+\eta S_{b}\right)}{L_{b}\left(S_{b}+S_{h} L_{b}\right)} \cdot \frac{S_{h} L_{b}}{S_{b}+2 L_{b} S_{h}}=\overline{t_{3}}
$$

Since $S_{b}$ is strictly positive, $L_{b} S_{h}<S_{b}+2 S_{h} L_{b}$ so that part 3 is negative if $T+t \leq \overline{t_{3}}<\overline{t_{2}}$.

Finally, as part 1 of (41) is positive and part 2 is negative, we conclude that the sign of the differential of the industrial damage with respect to the tax is undetermined. For $T+t>\overline{t_{3}}$, it is negative, but for $T+t<\overline{t_{3}}$ it is positive.

\section{Appendix 6}

The maximization of $S W$ with respect to $a$ and $T$ gives a single $a^{*}$, when the abatement function explicited as $C(a)=a_{0}+a_{1} a+a_{2} a^{2}$, with $a_{0}, a_{1}$ and $a_{2}$ positive :

$$
a^{*}=\frac{1}{4 L_{b} a_{2}}\left[\gamma_{f} N\left(L_{b} S_{h}+S_{b}\right)+2 L_{b}\left(N-a_{1}\right)\right]
$$

We also obtain two solutions for $T^{*}: T_{1}^{*}$ corresponds to the threshold above which the incompletely mixed configuration is no longer an equilibrium $: t+T_{1}^{*}=\overline{t_{2}}$. The second solution, that we retain, is as follows :

$$
t+T_{2}^{*}=\overline{t_{2}}\left[1+\frac{2}{S_{h}} \frac{\gamma_{f} S_{h} \eta\left(L_{b} S_{h}+S_{b}\right)-2\left(S_{b} \eta+S_{h} \tau\right)}{\gamma_{c} 3 L_{b} S_{h} S_{b} k\left(L_{b} S_{h}+S_{b}\right)-\gamma_{f} 2 \eta\left(2 L_{b} S_{h}+S_{b}\right)}\right]
$$

One can easily check that $\left\{a^{*}, T_{2}^{*}\right\}$ is a local maximum if $\gamma_{f}<\overline{\gamma_{f}}$; otherwise it is a saddle-point.

The efficient norm and tax parameters are affected by the social weights on damage in the following way :

$$
\frac{\partial a^{*}}{\partial \gamma_{c}}=0 \text { and } \frac{\partial a^{*}}{\partial \gamma_{f}}>0
$$




$$
\frac{\partial T^{*}}{\partial \gamma_{c}}>0 \text { if } \gamma_{f}<\overline{\gamma_{f}} \text { and } \frac{\partial T^{*}}{\partial \gamma_{f}}>0 \text { if } \gamma_{c}>\bar{\gamma}_{c}
$$

where the thresholds $\bar{\gamma}_{c}$ and $\overline{\gamma_{f}}$ are defined as follows :

$$
\overline{\gamma_{f}}=\frac{2\left(S_{b} \eta+S_{h} \tau\right)}{S_{h} \eta\left(L_{b} S_{h}+S_{b}\right)} \text { and } \overline{\gamma_{c}}=\frac{4}{3} \frac{\left(S_{b} \eta+S_{h} \tau\right)\left(2 L_{b} S_{h}+S_{b}\right)}{L_{b} S_{b} S_{h}^{2} k\left(L_{b} S_{h}+S_{b}\right)^{2}}
$$

Also, to ensure that $T_{2}^{*}<T_{1}^{*}$, hence that the solution is compatible with an incompletely mixed equilibrium, from equation (45) we know that the following must apply : either $\gamma_{f}>\bar{\gamma}_{f}$ and $\gamma_{c}<\overline{\overline{\gamma_{c}}}$ or $\gamma_{f}<\overline{\gamma_{f}}$ and $\gamma_{c}>\overline{\bar{\gamma}}_{c}$, where $\overline{\bar{\gamma}}_{c}=\bar{\gamma}_{c} \frac{\gamma_{f}}{\bar{\gamma}_{f}}$. 